\title{
Kinematic GPS survey as validation of LIDAR strips accuracy
}

\author{
Maurizio Barbarella and Cristian Gordini \\ Dipartimento di Ingegneria delle Strutture, dei Trasporti, delle Acque, del Rilevamento, \\ del Territorio (DISTART), Università degli Studi di Bologna, Italy
}

\begin{abstract}
As a result of the catastrophic hydrogeological events which occurred in May 1998 in Campania, in the south of Italy, the distinctive features of airborne laser scanning mounted on a helicopter were used to survey the landslides at Sarno and Quindici. In order to survey the entire zone of interest, approximately $21 \mathrm{~km}^{2}$, it was necessary to scan 12 laser strips. Many problems arose during the survey: difficulties in receiving the GPS signal, complex terrain features and unfavorable atmospheric conditions. These problems were investigated and it emerged that one of the most influential factors is the quality of GPS signals. By analysing the original GPS data, the traces obtained by fixing phase ambiguity with an On The Fly (OTF) algorithm were isolated from those with smoothed differential GPS solution (DGPS). Processing and analysis of laser data showed that not all the overlapping laser strips were congruent with each other. Since an external survey to verify the laser data accuracy was necessary, it was decided to utilize the kinematic GPS technique. The laser strips were subsequently adjusted, using the kinematic GPS data as reference points. Bearing in mind that in mountainous areas like the one studied here it is not possible to obtain nominal precision and accuracy, a good result was nevertheless obtained with a Digital Terrain Model (DTM) of all the zones of interest.
\end{abstract}

Key words LIDAR - GPS - DTM - landslide body - Sarno

\section{Introduction}

In 1998 a hydrogeological disaster caused landslides in the Campania territory, in the south of Italy. This event represented an environmental emergency, requiring a DTM to be provided as quickly as possible of part of the territory, such as for instance of the landslide slopes. In fact, after the topographical survey it

Mailing address: Dr. Cristian Gordini, Dipartimento di Ingegneria delle Strutture, dei Trasporti, delle Acque, del Rilevamento, del Territorio (DISTART), Università degli Studi di Bologna, Viale Risorgimento 2, 40136 Bologna, Italy; e-mail: cristian.gordini@mail.ing.unibo.it was possible to define the present shape of the surface of the landslide, the presence of the unstable masses which might become dangerous and the amount of the displaced volume; all this information is extremely useful for geotechnical application. Laser scanning is a recent survey technique that makes it possible to acquire a cloud of points of the zone of interest in a relatively short time and with remarkable intrinsic precision. The system has many applications in particular, these techniques prove useful in detecting zones at hydrogeological risk, in creating Digital Surface Models (DSM) and DTM of medium-large areas. To study the hydrogeological event which occurred in Campania, a LIDAR (LIght Detection And Ranging) flight was planned. The aim of this study was the evaluation of the accuracy and precision which can be achieved by joining many laser scanning strips to obtain a DTM in a difficult (very steep ground) and extensive area. 


\subsection{Characteristics of the area of interest and dynamics of the landslides}

The area of interest between Sarno, Episcopio and Quindici extends for about $21 \mathrm{~km}^{2}$, and is characterized by a complex morphology with slopes of up to $100 \%$. The landslides which occurred in 1998 were classified as debris flow according to Varnes (1978). In general the detachment of the material is sudden, the movement is slow at first and becomes fast in a very short time. Two particular conditions can be identified as the cause of the 1998 event: lithologic characteristics (loose rocks between stratum of limestone with the same inclination as the slope side) and the steep slopes of the sides. The urban development of the area without good planning also contributed to the disaster. A heavy shower aggravated the situation a few day before the catastrophic event.

\subsection{Laser scanning technology}

LIDAR is a scanning and ranging laser system that produces highly accurate and high-resolution topographic maps. The technology has been in existence for 20 years, but the commercial application for topographic maps has only developed within the last ten years (Baltsavias, 1999). Today, the entire process of airborne laser mapping is «highly automated, from flight planning, to data acquisition, to generation of DTM». Through the use of several sensors (GPS-INS, Laser Range Finder LRF) LIDAR makes it possible to obtain a cloud of raw data in the GPS geodetic frame. The scanning of the ground is the result of the combination of the movement of the aircraft with the deflection of the laser. With the LRF installed on an aircraft, it is possible to calculate the distance from the ground computed by the time the laser beam

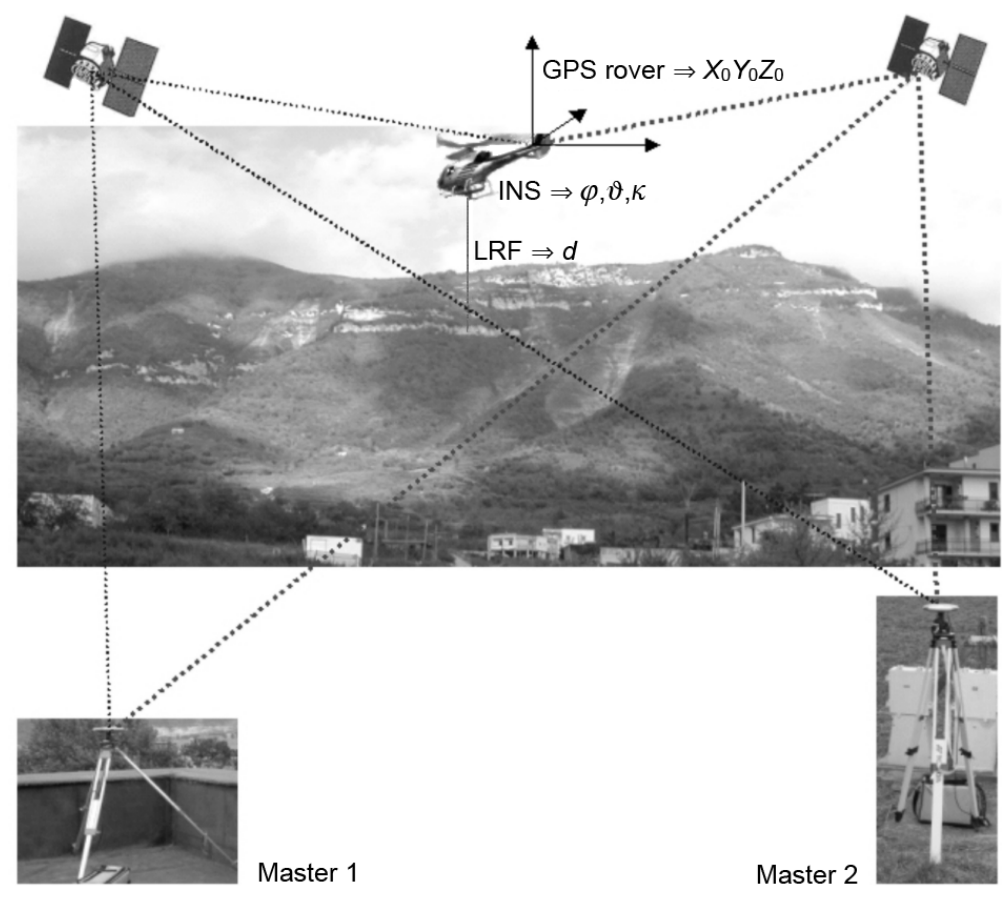

Fig. 1. LIDAR survey in Sarno landslide bodies. 
takes to travel to the ground and back. The position, pitch, roll and heading angle of the aircraft are determined by the GPS-INS system; consequently the sensor positions are also known (fig. 1 ). The system can also be equipped with a digital camera for visual documentation of the surveyed zone. GPS, INS, LRF and digital camera measurements are recorded during the flight and the GPS time synchronizes all the sensors. Laser sensor can record two echoes, this characteristic makes it possible to penetrate wooded zones and obtain direct measurements on the terrain surface. In fact, in forest areas, multiple responses are useful to obtain both vegetation and terrain points. Figure 2 shows two possibilities for the laser impulse: for example the first response is given by the vegetation and the second by the terrain; as fig. 2 shows, outliers are possible in

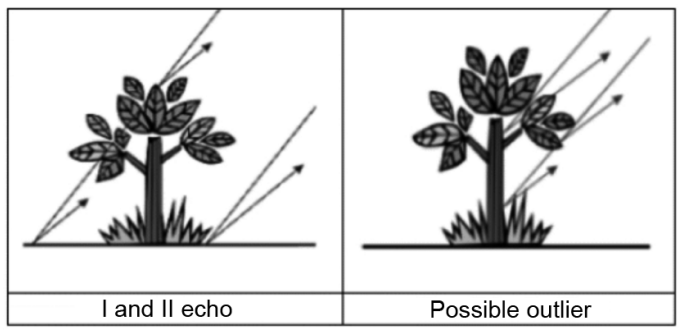

Fig. 2. Double echo. this automatic classification. The latest laser scanning generation can record the radiometric response of material; this is a supplementary but important information. In the Sarno survey, a helicopter with a Saab TopEye LIDAR system was used.

\subsection{Planning of the survey}

When the area to be surveyed is extensive, it is necessary to scan several parallel strips, which should overlap to a sufficient extent so that the strips can be joined to realize a DTM and the repeatability of the data in the overlapping zone can be checked. In this case study the area of interest was $21 \mathrm{~km}^{2}$ and the flight plan was defined accordingly both to the application for a large scale $(1: 2000)$ and to the safety of the helicopter. Having chosen the helicoptermounted TopEye system and the ground point density $\left(1\right.$ per $\left.\mathrm{m}^{2}\right)$, all the other parameters i.e. flight height, helicopter velocity, strip width, number of strips and overlap were determined. Figure 3 summarises the flight plan data (Barbarella et al., 2002). A digital camera was also programmed to obtain photographic documentation of the surveyed zone. There are several factors in obtaining precise and accurate LIDAR data. These are, for example, the GPS solution and the flight stability. The GPS solution is explained in the follow section. The flight

Flight plan parameters
- Flight altitude: $375 \mathrm{~m}$
- Speed: $92.5 \mathrm{~km} / \mathrm{h}$
- LRF angle: $20^{\circ}$
- Overlap: $12 \%$
- Echoes: 2
- Strip width: $273 \mathrm{~m}$
- Point densities: 1 per $\mathrm{m}^{2}$
- Point frequencies: $7000 \mathrm{~Hz}$
- Number of strips: 12
- Digital camera calibrated

Fig. 3. Parameter of plan and strips obtained. 
stability can be disturbed by atmospheric conditions, with a consequent increase in roll and pitch angle variations, causing gaps in the data if the lateral overlap percentage is not sufficient. Many problems arose during the survey: difficulties in receiving the GPS signal, complex terrain features and unfavorable atmospheric conditions. In fig. 3 the strips obtained are shown in 3D.

\subsection{Interference with the GPS signal}

Interferences with the GPS signal can sometimes interrupt rover reception. Ambiguity resolution is obtained, in general, with the OTF algorithm, which makes it possible to achieve positioning within $10 \mathrm{~cm}$ precision. However a smoothed differential GPS solution is guaranteed with a metre of precision when the OTF algorithm is unable to fix the ambiguity. The carrier phase ambiguity resolution is a relevant factor for DTM final accuracy and precision (Al-Bayari, 2000). In the Sarno LIDAR survey Radio Frequency Interference (RFI), with GPS signal has been shown either by loss of look of L1 and L2 frequencies or just by loss of L2 and in some case by loss of the code. These interferences, probably due to radar activities, caused several problems. In particular, difficulties in maintaining the flight plan navigation and problems in collecting raw data. An analysis of the GPS files made it possible to isolate OTF from smoothed DGPS (bold and thin line in fig. 8a respectively) solution. Conscious of the fact that the strips were obtained with a precision different from what was expected, the LIDAR data were nevertheless processed.

\section{Raw data processing}

The laser strips consist of 22 million points, supplied as raw data in the WGS84 system by the firm that carried out the survey. The laser strips were subsequently incorporated in the Gauss-Boaga system with a seven-parameter similarity transformation (Barbarella, 1992). The seven parameters of transformation were estimated by a GPS network made on the entire zone of interest, and the Molodensky model was used by means of the coordinates of four vertexes of the national geodetic GPS network (the so-called IGM95) and some benchmarks of a levelling network. Utilizing TerraScan ${ }^{\mathrm{TM}}$ software by TerraSolid ${ }^{\mathrm{TM}}$, each strip was edited: vegetation and building points were classified and all subsequent analysis and processing refer to ground points (points of terrain) only. To have both DTM and DSM it is necessary recognize the surface to which the laser response belongs. This operation is defined as point classification. Table I reports an extract of the ASCII file, the output of the laser system; when the number in the first column is the same (bold type) as the previous one, the echo was double. Automatic classification is based on the recognition of echoes: for example in wooded zones the first echo is, reasonably, a point belonging to the foliage of a tree and can be classified as vegetation; the second echo, on the other hand, is probably a point of terrain and classified as a ground point. Unfortunately, however, the second echo can sometimes be recorded incorrectly, since the laser may strike the trunk of tree as the second point (see fig. 2). To have an accurate DTM it is therefore necessary to edit the data very carefully (changing the points incor-

Table I. Ascii file: example of output of LIDAR TopEye system, in WGS84 coordinates.

\begin{tabular}{cccccc}
\hline \hline Echo & Time GPS $(\mathrm{s})$ & Latitude $\left({ }^{\circ}\right)$ & Longitude $\left({ }^{\circ}\right)$ & Height $(\mathrm{m})$ & Radiometric \\
\hline 1 & 100505.0002 & 40.84496906 & 14.62097249 & 831.672 & 13.2 \\
2 & 100505.0005 & 40.84492823 & 14.62098154 & 831.586 & 13.9 \\
3 & 100505.0008 & 40.84498731 & 14.62099071 & 831.523 & 16.2 \\
$\mathbf{4}$ & 100505.0010 & 40.84500389 & 14.62100554 & 834.873 & 1.1 \\
$\mathbf{4}$ & 100505.0010 & 40.84499675 & 14.62099976 & 831.530 & 14.0 \\
\hline
\end{tabular}


rectly classified). In this case the algorithm utilized is Ground implemented by TerraScan ${ }^{\mathrm{TM}}$ software on the adaptive filter principle (Axelsson, 1999): the algorithm works with a TIN (Triangular Irregular Network) structure constructed with a few laser points, all the other points are added with an iterative procedure of densification (Barbarella and Fazio, 2001). The parameters to be used in the algorithm were chosen according to morphologically homogeneous zones: Quindici town, Episcopio town (nearly plain, inhabited surfaces), landslides in Quindici, landslides in Sarno and Episcopio (steep slopes), upland plain (nearly plain, uninhabited). In the morphological boundary zones the editing required greater attention, see longi-

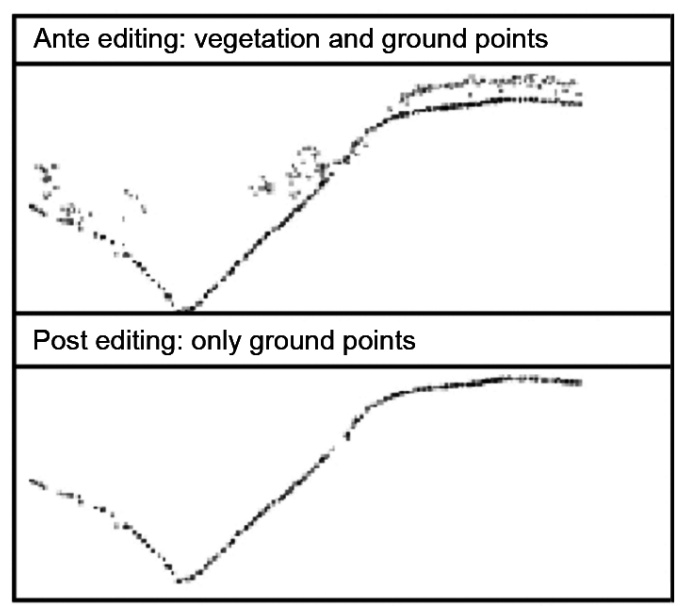

Fig. 4. Automatic classification utilizing double echoes. tudinal section in fig. 5. After the editing, only the ground points $50 \%$ of the initial approximately 11 million points see fig. 4) were utilized for the subsequent analyses. The new point density was about 0.5 points per $\mathrm{m}^{2}$.

\section{Analysis of data reliability in overlapping areas}

The result of the editing process, in this case of interest, is raw data of the ground points for each strip. Since these points should represent, together, a terrain surface, it is necessary to verify the precision and the accuracy of the data strips to analyze them in overlapping areas. LIDAR data are, in fact, acquired in strips. Since the data are acquired in a strip-wise mode, the adjustment needs to correct for both relative and absolute errors. The relative corrections remove, or reduce, discrepancies between strips in overlapping areas, and the absolute corrections are derived from comparisons of laser data with ground control points or ground features. Altimetric differences for each pair of strips, in the overlapping area, can be calculated by the $Z_{\text {res }}=Z_{\text {dat }}-Z_{\text {grd }}$ formula, where $Z_{\text {dat }}$ is the height of the raw data (or kinematic points, see fig. 6) of the first strip and $Z_{\mathrm{grd}}$ is the height value of the interpolated points of the second strip. With this method all $Z_{\text {res }}$ are calculated in all overlapping areas; means, standard deviations and histograms of $Z_{\text {res }}$ for each area show different results: for flat areas (like the towns of Quindici and Episcopio and the upland plain) the means range from 1 to $3 \mathrm{~m}$, while in the landslide zones (where the slopes reach up to

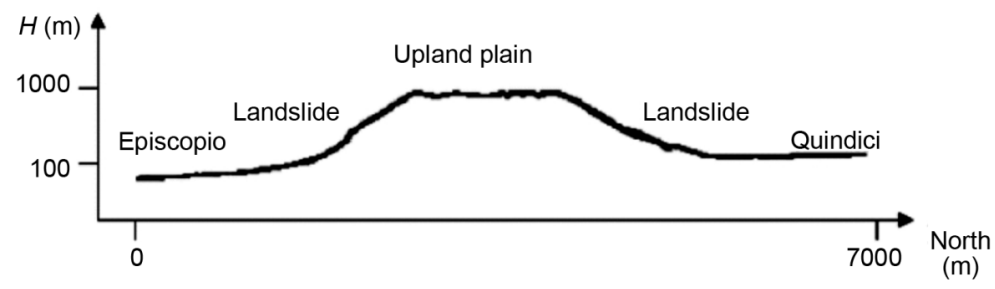

Fig. 5. A longitudinal cross-section along the axis of strip six. 
$100 \%)$ the $Z_{\text {res }}$ means showed higher values; from 2 to $6 \mathrm{~m}$ (see table V, columns 4 and 5). It should be borne in mind that it is not possible to achieve the nominal precision of LIDAR in these complex areas, and the interference to the GPS signal reduced this precision even more. The different precision between the DGPS and the OTF solutions can introduce an altimetric shift between adjacent strips. The results of the altimetric residuals analysis showed that the $Z_{\text {res }}$ values are not in a range for the calculation of a DTM within $50 \mathrm{~cm}$ level of accuracy. It was therefore decided to carry out a kinematic GPS survey of the ground to check the strip accuracy.

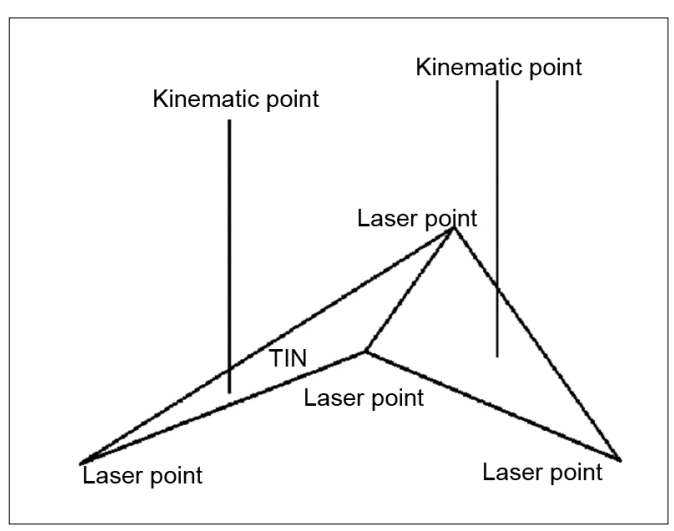

Fig. 6. $Z_{\text {res }}$ between LIDAR data interpolated by TIN and kinematic points.

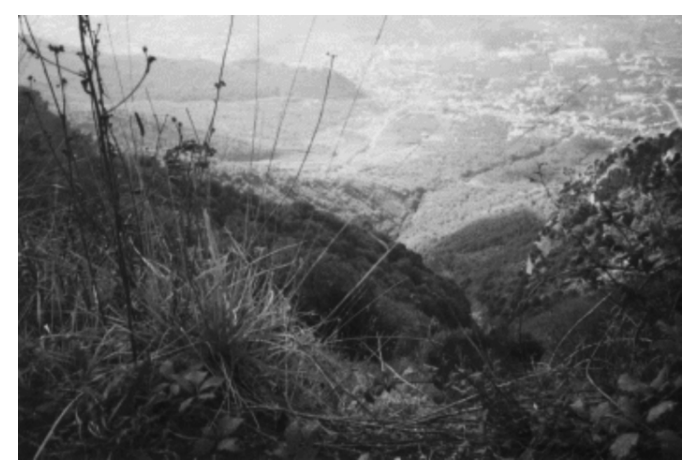

Fig. 7. Photo of landslide body called Sa10.

\section{Kinematic GPS survey for evaluation of the laser data accuracy}

To have an external control of the laser data and to evaluate the relative and absolute accuracy of the strips, kinematic and Real Time Kinematic (RTK) GPS surveys were planned. Initially it was planned to take measurements along the longitudinal axis of overlapping strips, but steep slopes, dense vegetation and the absence of paths did not allow continuous profiles along the laser strip to be carried out. During the planning stage a further problem emerged in addition to the electromagnetic interferences with the GPS signal: there are in fact zones where access is difficult or impossible (see photo in fig. 7), as in the landslide bodies. Three trajectories were therefore planned, two in the centre of the towns of Quindici and Episcopio and the last in the middle of the strips, on an upland plain of the mountain (1000 $\mathrm{m}$ in altitude) where there is a narrow road. Isolated points were also identified by photos and radiometric data of the laser points of recognizable flat areas (roofs of buildings, car parks and sports fields) to make it possible to evaluate the planimetric offset. Figure $8 \mathrm{~b}$ shows the contours of the laser strips and the three GPS trajectories planned. The survey was performed with double frequency Javad and Trimble receivers, by using two vertexes of the 1998 network (Quindici and Sarno) as the master point. The phase corrections were transmitted by GSM modem from master to rover for the RTK survey. Unfortunately, the presence of dense vegetation, building obstructions and electromagnetic interferences with the GPS signal made the survey not as precise as would have been possible without these obstacles. The kinematic data were processed with different software applications - Geogenius and Pinnacle - and the differences obtained were fully compatible within the RMS. It was decided to use the Pinnacle application. Table II shows the Pinnacle results: RMS, standard deviation of mean values and number of satellites; in Episcopio the maximum number of visible satellites was six but for most of the time only five were visible. Although the survey was not as precise as would have been possible without any distur- 

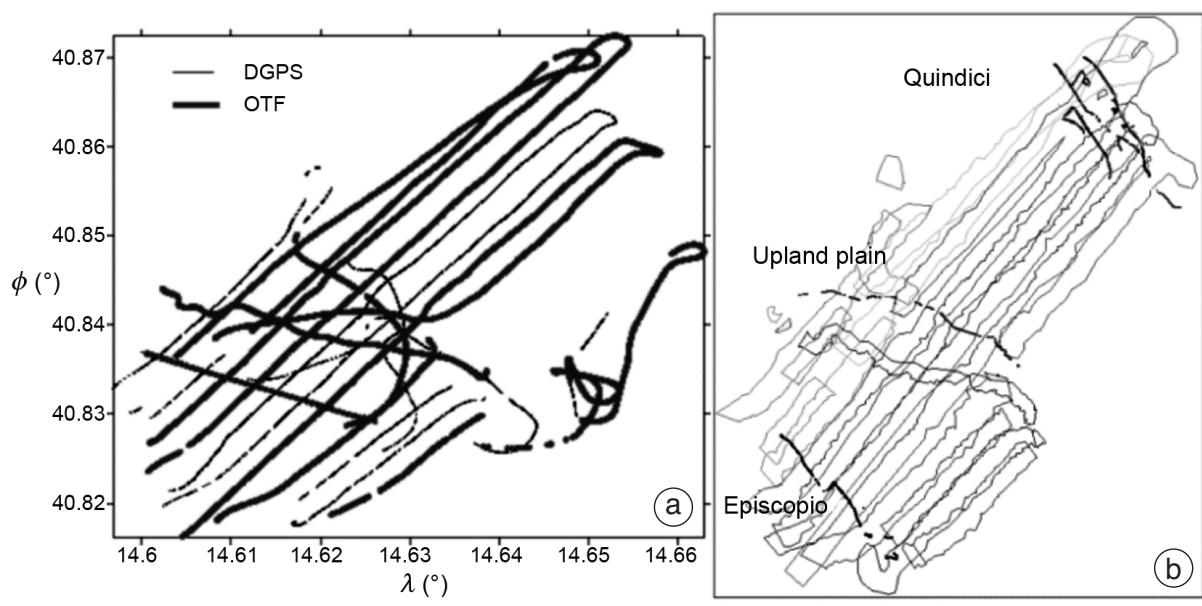

Fig. 8a,b. a) OTF and DGPS solutions. b) Contour of strips and trajectory obtained by GPS kinematic.

Table II. Results of Pinnacle GPS elaboration.

\begin{tabular}{|c|c|c|c|c|c|}
\hline & Quindici & \multicolumn{2}{|c|}{ Upland plain } & \multicolumn{2}{|c|}{ Episcopio } \\
\hline RMS (m) & 0.1 & & 4 & & \\
\hline PDOP & 1.9 & & 7 & & \\
\hline No. SVs & 6 & 7 & 8 & 5 & 6 \\
\hline$\%$ & 16 & 59 & 17 & 4 & 38 \\
\hline
\end{tabular}

bance, the trajectories obtained were used as a reference to analyse the accuracy of strip data.

\subsection{External accuracy evaluation}

To evaluate the external accuracy the trajectory data were transformed in the national geodetic system (Gauss-Boaga) adopted for the laser data, utilizing the same seven parameters of similarity transformation previously used. A first qualitative comparison between the kinematic trajectory and the laser data shows systematic differences in the altimetric component. As shown in fig. 9 the strips are displayed in different colors and many cross-sections are drawn along the GPS trajectory (in blue in fig. 9); for the qualitative analysis three cross-sections are reported respectively for each group of strips: Quindici, upland plain and Episcopio, but a detailed analysis was done by computing $Z_{\text {res }}$. To determine $Z_{\text {res }}$ in altimetry the formula explained in Section 3 was used. Therefore the residual values in altitude are calculated by using the kinematic survey as a reference, and some elementary statistics are obtained for these differences for each strip involved (table III). Those values were checked in each strip in many cross-sections to see any systematic differences. From table III it is possible to note that the differences between the kinematic ground survey and the laser data are quite similar for the same strip: for strip 3 the mean of the difference between the kinematic points varied from 4.7 to $5 \mathrm{~m}$ with a range of $0.3 \mathrm{~m}$; for strip 6 , the mean varied from 7.6 to $7.9 \mathrm{~m}$ with a range of $0.3 \mathrm{~m}$, for strip 7 varied from 6.1 to $7 \mathrm{~m}$ with a range of $0.9 \mathrm{~m}$; for strip 8 varied from 4.3 to $5.6 \mathrm{~m}$ with a range of $1.3 \mathrm{~m}$. Some considerations can be drawn: the strips obtained with the OTF solution (fixed ambiguity) present offsets not always less than those of the strips with the DGPS solutions, so it is not possible to rely completely on the type of solution of the GPS trajectory to define a set of strips as a reference. The differences between the kinematic and laser surveys are due to the fact that the GPS trajectory of the flight is not linked to the same network as the kinematic 


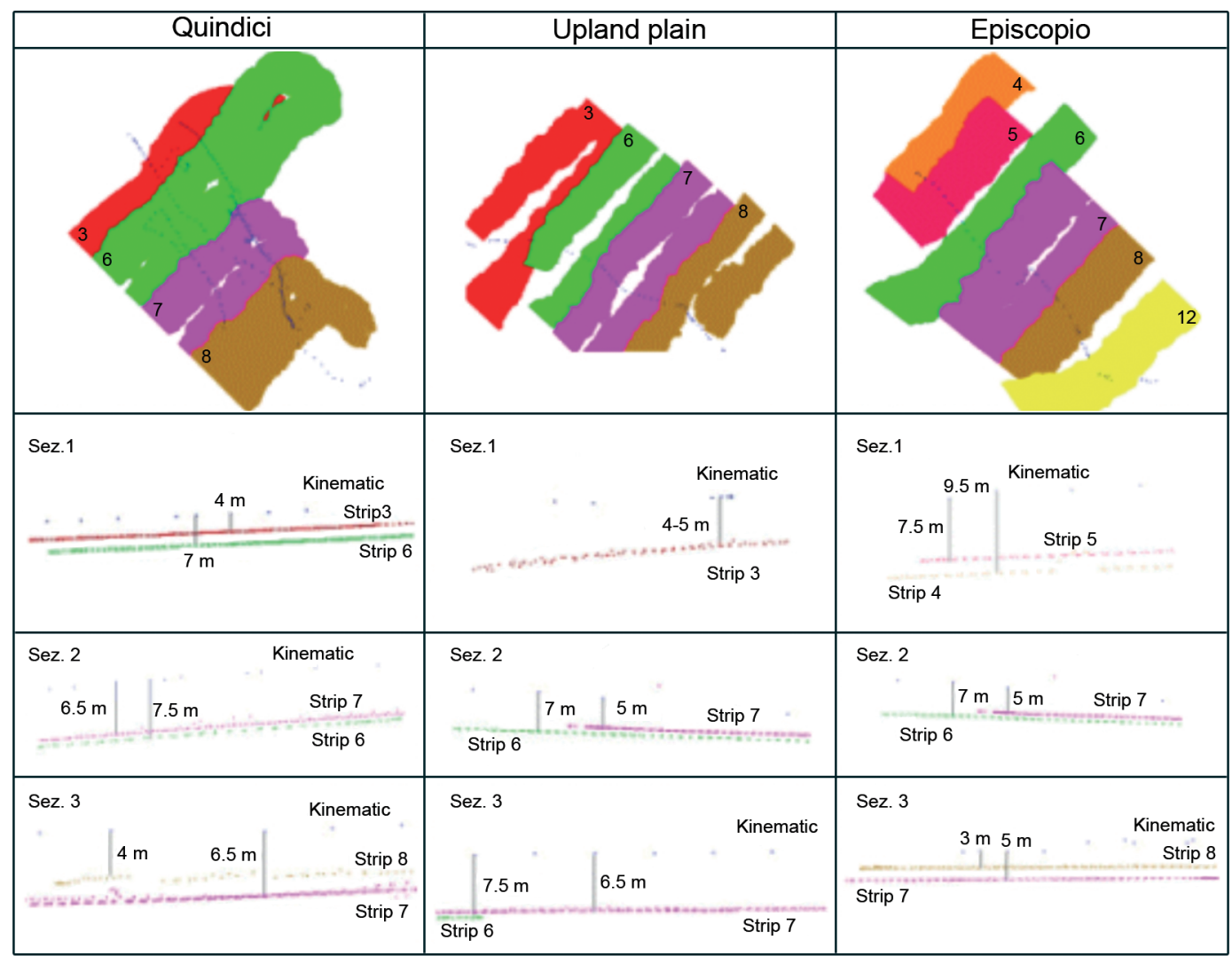

Fig. 9. Qualitative analysis of altimetric residuals between strips in overlapping areas.

Table III. Altimetric offset resulting from analysis of external accuracy.

\begin{tabular}{ccccc}
\hline \hline \multirow{2}{*}{ Check Areas } & & Kinematic-strip $H(\mathrm{~m})$ & \\
& & Mean & Standard deviation & Sample \\
\hline \multirow{2}{*}{ Quindici } & Strip 3 (fixed) & 4.7 & 2.2 & 433 \\
& Strip 6 (fixed) & 7.9 & 1.7 & 563 \\
& Strip 7(DGPS) & 6.3 & 4.0 & 472 \\
& Strip 8(fixed) & 4.7 & 1.4 & 395 \\
Upland plain & Strip 3 (fixed) & 5.0 & 0.5 & 50 \\
& Strip 6 (fixed) & 7.8 & 1.2 & 96 \\
& Strip 7(DGPS) & 7.0 & 0.3 & 129 \\
Episcopio & Strip 8(fixed) & 5.6 & 2.3 & 14 \\
& Strip 6 (fixed) & 7.6 & 1.0 & 46 \\
& Strip 7(DGPS) & 6.1 & 2.2 & 92 \\
& Strip 8(fixed) & 4.3 & 2.7 & 65 \\
& Strip 12 (DGPS) & 5.9 & 1.5 & 36 \\
\hline
\end{tabular}


survey: the master position was obtained from a permanent station (Matera, about $170 \mathrm{~km}$ away) as shown by an investigation based on the original flight data, subsequently delivered by the firm which carried out the survey. In fact the latitude, longitude and height coordinates, in the WGS84 system, of the Quindici and Sarno vertexes from the 1998 network present an offset with respect to the same coordinate calculated by static baseline from the Matera GPS permanent station. These offsets are $+4 \mathrm{~m}$ in northing, $-4 \mathrm{~m}$ in easting and about $-2 \mathrm{~m}$ in height. This is probably the cause of the differences between the laser and kinematic surveys.
To make the laser data homogeneous with the network calculated in 1998 the kinematic survey was used as a reference.

\subsection{Estimation of altimetric offset on recognizable flat areas}

Another way to check the presence and the extent of offset can be to consider areas or recognizable buildings on the DTM (also using the images obtained by the digital camera and the radiometric response of the LRF) and then to measure the position of some detail on the

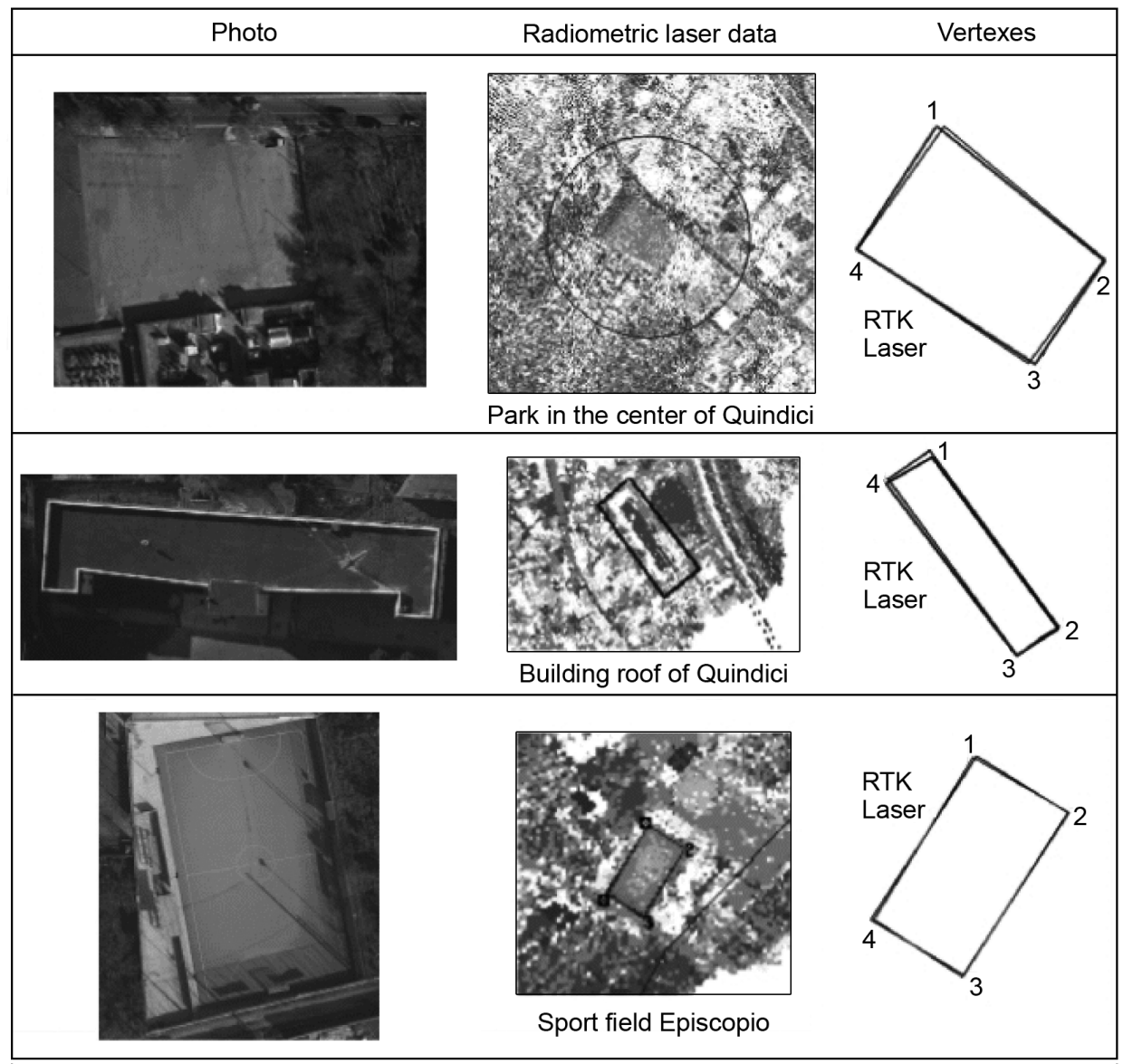

Fig. 10. Analysis of 3D residuals between points in recognizable areas. 
ground: edges of buildings, edges of fields, etc. (Casella and Spalla, 2000). To evaluate those offsets determined in the previous section, the points of the RTK survey were used, with three different cases: four vertexes of a car park and a roof in Quindici, four vertexes of a sports field in Episcopio. It is known that is not possible to recognize in the set of laser data some particular points to be subsequently measured in the field; despite this, as shown in fig. 10, by utilizing photo images and radiometric laser information it is possible to isolate these points which are, probably, points of a recognizable flat area and a polygon can subsequently be drawn. The differences between RTK and laser points can be evaluated by polygon or by single point, in first approximation. In the three cases mentioned above the planimetric offsets were evaluated point by point and the differences vary between $0.5-2 \mathrm{~m}$, while the altimetric offset confirmed the results previously obtained (table IV). In order to make the laser survey homogeneous with the kinematic survey some constants were determined by average height differences.

\section{Laser strip adjustment}

Many studies on laser strip adjustment are present in the literature (Burman, 2000; Maas,

Table IV. Differences 3D between RTK and LIDAR coordinates in Gauss-Boaga system.

\begin{tabular}{crrrrrrrrrr}
\hline & \multicolumn{8}{c}{$\begin{array}{c}\text { Coordinate differences RTK-Laser (m) Gauss-Boaga System } \\
\text { Car Park }\end{array}$} & \multicolumn{7}{c}{ Building roof } & \multicolumn{3}{c}{ Sport field } \\
\hline Point & $\Delta N$ & $\Delta E$ & $\Delta H$ & $\Delta N$ & $\Delta E$ & $\Delta H$ & $\Delta N$ & $\Delta E$ & $\Delta H$ \\
1 & 0.3 & -0.4 & 5.5 & 1.9 & -0.6 & 8.1 & 0.2 & 0.8 & 6.4 \\
2 & -0.4 & 0.9 & 5.2 & 0.5 & 0.2 & 8.0 & 0.1 & -0.2 & 6.5 \\
3 & -0.3 & 0.4 & 5.4 & 1.3 & 0.6 & 8.1 & 0.3 & 0.3 & 6.4 \\
4 & -0.2 & -0.2 & 4.9 & -0.4 & 0.5 & 8.0 & 0.1 & -0.6 & 6.5 \\
\hline
\end{tabular}

Table V. Results of analysis in overlapping areas.

\begin{tabular}{ccccccc}
\hline \hline $\begin{array}{c}\text { Morphologically } \\
\text { homogeneous areas }\end{array}$ & \multicolumn{2}{c}{$Z_{\text {res }}(\mathrm{m})$} & \multicolumn{2}{c}{ Before adjustment } & \multicolumn{2}{c}{ After adjustment } \\
Check area & Sample & Mean & Standard deviation & Mean & Standard deviation \\
\hline Quindici & Strip (3-6) & 30618 & 2.9 & 0.6 & 0.1 & 0.5 \\
& Strip (6-7) & 28425 & -0.8 & 0.4 & 0.1 & 0.4 \\
& Strip (7-8) & 7101 & -1.8 & 0.7 & -0.2 & 0.6 \\
Landslide & Strip (3-6) & 41922 & 2.2 & 1.4 & 0.8 & 1.2 \\
& Strip (6-7) & 40581 & -1.7 & 1.6 & -0.9 & 1.3 \\
Upland plain & Strip (3-6) & 30575 & 2.2 & 1.0 & 0.5 & 1.0 \\
& Strip (6-7) & 8274 & -0.8 & 1.8 & -1.0 & 1.3 \\
& Strip (7-8) & 14289 & -1.9 & 2.0 & 0.4 & 1.2 \\
Landslide & Strip (1-2) & 1806 & 6.2 & 0.9 & 0.8 & 1.3 \\
& Strip (11-12) & 2403 & 2.8 & 1.5 & 0.7 & 1.2 \\
Episcopio & Strip (6-7) & 9575 & -1.1 & 0.3 & 0.5 & 0.3 \\
& Strip (7-8) & 3508 & -1.0 & 0.2 & -1.1 & 0.2 \\
\hline
\end{tabular}




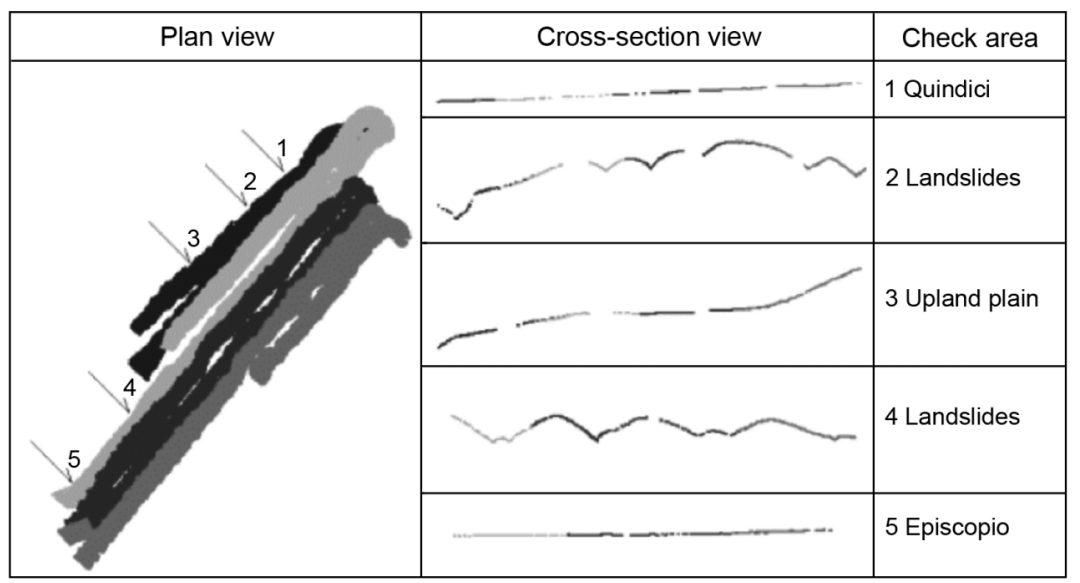

Fig. 11. Plan and cross-section view of adjusted strips.

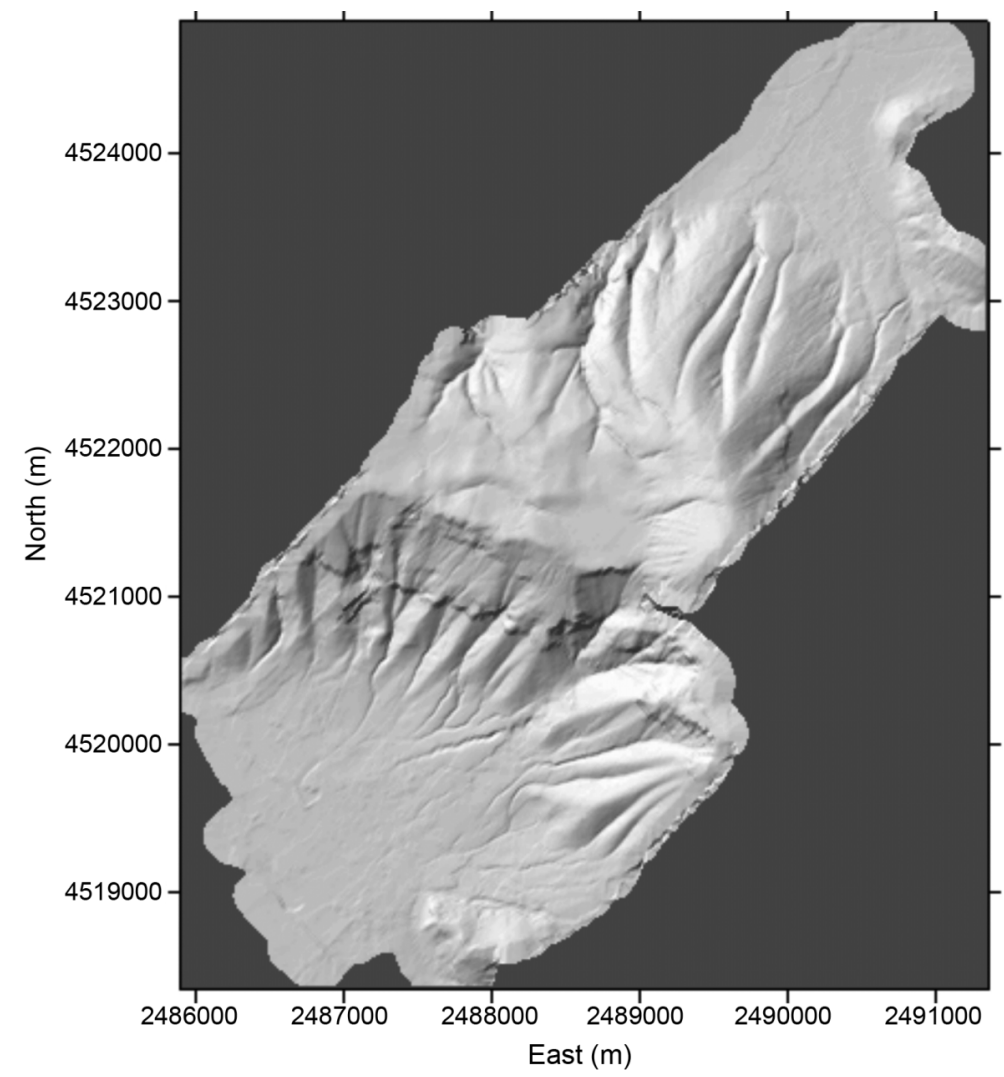

Fig. 12. DTM. 
2000; Vosselman, 2002). These studies are based on the minimum square principle to minimize the residual differences between two DTMs which cover the same area, presuming that these two DTMs have an intrinsic accuracy and precision, and that the algorithms were tested only in flat areas. In the case of Sarno these requirements are absent, and it is therefore necessary to apply an empirical adjustment. After the precision and accuracy analyses, it is possible to calculate a constant for each ground point in the strip to adapt the strips to the kinematic survey. With these corrections a set of points is obtained which can be used to calculate a grid-structured DTM by interpolation or triangulation. The results of the adjustment show mean differences between $0.5-1 \mathrm{~m}$ between adjacent strips in the same overlapping areas investigated in section three, see table V columns 6 and 7. Figure 11 shows a plan view of strips adjusted and the cross-section views of five check areas of strips $3,6,7,8$.

\section{Results and analyses}

A complete DTM of the zone of interest was calculated with adjusted strip data. The Kriging algorithm with a $10 \mathrm{~m}$ grid pitch was used. During the gridding phase, areas without laser point were also interpolated, making it possible to obtain a complete model of the terrain. To ensure more reliable results, it is therefore advisable to isolate the zones where there is no information and if necessary to integrate the laser data with a photogrammetric survey (determining the mean height of the vegetation from the laser data). Figure 12 shows the DTM obtained, in which it is possible to see how the model actually represents the terrain; the strata of about $20 \mathrm{~m}$ of limestone can in fact be seen.

\section{Conclusions}

LIDAR data make possible to obtain a cloud of points with considerable density and acceptable precision to permit many engineering applications and studies. The careful analysis of the GPS data allowed to isolate smoothed DG-
PS and OTF fixed ambiguity solutions for the trajectories. The analyses performed on overlapping zones and the comparisons with the kinematic field survey made it possible to determine some averages of altimetric differences to apply as constants to each strip. After applying the adjustment constants on each point of the strip, the average residual differences in the same overlap zones become about $50-100 \mathrm{~cm}$. It was also seen that many of the problems observed in the flight, such as GPS signal interference, dense vegetation and complex morphology, were also encountered in the kinematic field survey. The absence of information between a few pairs of strips remains an important factor. It will be necessary that in such morphologically difficult zones the project overlap is increased (at least 20\%) even if this increases the costs of the flight and processing of the data. Even with the limits pointed out above, the LIDAR survey did make it possible to acquire a set of data for the construction of a high quality DTM on a very large area $\left(21 \mathrm{~km}^{2}\right)$, with a degree of detail and information of the ground that could not be obtained with other techniques. In conclusion, the DTM can be considered a good result, calculated with one meter of mean precision, (although this precision is not uniform on the whole area), describing the true surface pattern of the ground without the vegetation cover.

\section{REFERENCES}

Al-BAyARI, O. (2000): Some problems in kinematic airborne laser survey, in Reports on Geodesy 6th Geodetic Millennium Meeting Poland-Italy.

Axelsson, P. (1999): Processing of laser scanner data, algorithms and applications, ISPRS J. Photogramm. Remote Sensing, 54 (2-3), 138-147.

Baltsavias, E. (1999): Airborne laser scanning: basic relations and formulas, ISPRS J. Photogramm. Remote Sensing, 54 (2-3), 199-214.

Barbarella, M. (1992): Uso del GPS per l'inquadramento delle reti, Boll. SIFET, 4, 49-68.

Barbarella, M. and C. FAZIO (2001): A procedure of the classification and editing of laser data in order to obtain DTMs of landslide, in Workshop on 3D Digital Imaging and Modeling Application of Heritage, Industry, Medicine and Land, 2-4.

Barbarella, M., C. Gordini and V. Lenzi (2002): Analisi di un blocco di strisciate laser scanning, in Atti della VI Conferenza ASITA, 299-306. 
Burman, H. (2000): Adjustment of laser scanner data for correction of orientation errors, in XIX ISPRS Congress, Commission III, 16-22 July, Amsterdam, The Netherlands, ISPRS Arch., XXXIII (B3/1), 119-126.

Casella, V. and A. Spalla (2000): Estimation of planimetric accuracy of laser scanning data. Proposal of method exploiting ramps, in XIX ISPRS Congress, Commission III, 16-22 July, Amsterdam, The Netherlands, ISPRS Arch., XXXIII (B3/1), 157-163.

MAAs, H.G. (2000): Least-squares matching with airborne laser scanning data in a tin structure, in XIX ISPRS Con- gress, Commission III, 16-22 July, Amsterdam, The Netherlands, ISPRS Arch., XXXIII (B3/1), 548-555.

VARNES, D.J. (1978): Slope Movement types and processes, in Landslides - Analysis and Control, edited by R.L. SCHUSTER and R.J. KRIZEK, National Academy of Sciences Transportation Research Board, Special Rep. No. 176, 12-33.

Vosselman, G. (2002): On the estimation of planimetric offsets in laser altimetry data, in ISPRS Commission III, Symposium 2002, September 9-13, 2002, Graz, Austria, ISPRS Arch., XXXIV (3A), 375-380. 